Int. J. Electrochem. Sci., 14 (2019) 4453 - 4468

International Journal of

ELECTROCHEMICAL

SCIENCE

WWW.electrochemsci.org

Mini review

\title{
Progress in the Photoelectrochemical Biosensors for the Detection of MicroRNAs: A Review
}

\author{
Linlin $\mathrm{Hou}^{1^{*}}$, Binbin Zhou ${ }^{1,3}$, Yuxin $\mathrm{Li}^{1}$ and Ming $\mathrm{La}^{2^{*}}$ \\ ${ }^{1}$ Henan Province of Key Laboratory of New Optoelectronic Functional Materials, College of \\ Chemistry and Chemical Engineering, Anyang Normal University, Anyang, Henan 455000, People's \\ Republic of China \\ ${ }^{2}$ College of Chemistry and Chemical Engineering, Pingdingshan University, Pingdingshan, Henan \\ 467000, People's Republic of China \\ ${ }^{3}$ Hunan Institute of Food Quanlity Supervision Inspection and Research, Building B, No. 238, Ave. \\ Timesun, District Yuhua, Changsha, Hunan 410111, People's Republic of China \\ *E-mail: linlin9918@163.com (L. H.); mingla2011@163.com (M. L.)
}

doi: $10.20964 / 2019.05 .33$

Received: 7 January 2019 / Accepted: 13 February 2019 / Published: 10 April 2019

MicroRNAs (miRNAs) have been regarded as the new targets for cancer diagnosis and treatment. Photoelectrochemical (PEC) biosensors with the advantages of miniaturization, high sensitivity and low background signal have been developed for miRNAs detection in recent years. This work focused on the recent progress in the design strategies for miRNAs detection with PEC biosensors.

Keywords: MicroRNAs; photoelectrochemistry; biosensors;

\section{FULL TEXT}

(C) 2019 The Authors. Published by ESG (www.electrochemsci.org). This article is an open access article distributed under the terms and conditions of the Creative Commons Attribution license (http://creativecommons.org/licenses/by/4.0/). 